\title{
NATUREZA E CIÊNCIAS SOCIAIS
}

\author{
Gloria Maria Vargas*
}

\begin{abstract}
Resumo: A construção do sentido do termo natureza abrange diferentes áreas do conhecimento e tem sido objeto de reflexão tanto das ciências naturais quanto sociais. Nos desdobramentos do conhecimento produzido sobre esta temática existem diversas abordagens que, da perspectiva das ciências sociais, podem ser identificadas. O propósito deste artigo é considerar algumas dessas abordagens e relacioná-las com as novas práticas sociais que determinam formas de intervenção inéditas sobre a natureza, e que colocam questões para estas ciências, enquanto produtoras de conhecimento sobre o tema. De igual forma, explicita-se a substituição deste termo pelo de ambiente e, posteriormente, o aparecimento do desenvolvimento sustentável, como parte do cabedal conceitual com que a problemática em torno das relações natureza-sociedade é abordada nas ciências sociais.
\end{abstract}

Palavras-chave: natureza, ciências sociais, relações sociedadenatureza, ambiente, desenvolvimento sustentável.

\section{Introdução}

A noção de natureza vem sendo modificada e, de alguma maneira, precisada ao longo da evolução das ciências naturais e sociais. No primeiro caso, apresentando-se como campo ontológico autônomo, passível de experimentação e tomando como foco de análise suas leis e regularidades; no segundo, como resultado de desdobramentos do conhecimento e da história. Neste sentido, as

* Doutora em Geografia Humana e Pesquisadora do CNPq no Núcleo de Pesquisa em Democratização e Desenvolvimento da Universidade de São Paulo (NADD/ USP).

Artigo recebido em 11 ago. 2003; aprovado em 27 set. 2003. 
conceituações produzidas sobre o termo natureza apresentam diferenças muito expressivas, que acabam por redefini-la constantemente enquanto objeto de conhecimento, percorrendo caminhos que vão desde a geografia e a antropologia ecológica, até a biologia e a física.

Uma revisão dessas abordagens nos permite constatar que, em grande medida, elas recriam uma visão dualista da natureza, definida como oposição ao social ou à cultura. Isto se evidencia já a partir do final do século XIX, quando do debate epistemológico sobre os métodos e campos específicos das ciências da natureza e da sociedade, momento em que se estabelece a natureza como um âmbito material independente e autônomo da sociedade e da cultura.

O propósito deste artigo é considerar algumas dessas abordagens e relacioná-las com as novas práticas sociais que vêm determinando formas inéditas de intervenção sobre a natureza, e que, por sua vez, colocam questões para as ciências sociais enquanto área produtora de conhecimento sobre esta temática. Pretende-se ainda realizar uma rápida análise sobre os novos termos que vêm sendo utilizados nas ciências sociais, especificamente o termo ambiente e suas relações com o desenvolvimento sustentável.

\section{O "problema" da natureza}

Não há dúvida de que o "problema da natureza" é um assunto que ronda as ciências sociais de diversas maneiras. As dificuldades surgem quando se pretende determinar se a natureza é ou deve ser objeto do seu estudo, se ela é o arcabouço da vida social ou, ao contrário, uma categoria separada do social. Independentemente das respostas a estas perguntas, é inegável que o "problema da natureza" está fadado a aparecer. A reação que estas perguntas suscitam, bem como a variedade de respostas e, portanto, de abordagens que delas se desprendem, nos permite fazer uma primeira afirmação: existe evidentemente uma relação de tensão entre as ciências sociais e a natureza. Ela apenas reflete a tensão existente nas relações que se 
costuma chamar de "natureza-sociedade", expressão que por si só já explicita a dicotomia usualmente presente na abordagem. Mas, será que essa forma de equacionar a questão nos ajuda na compreensão dessas tensões?

As novas práticas sobre a natureza demonstram uma diversidade de formas de intervenção que vão desde a exploração dos recursos naturais e a criação de ilhas de conservação e preservação, até a mais recente incursão no material genético das células. Essas práticas refletem algumas visões preponderantes que sobre ela se generalizam e que são incorporadas socialmente, dando espaço a novas formas de intervenção. Uma instância onde se produzem, incorporam e legitimam essas visões é a própria produção científica do conhecimento, tanto da perspectiva das ciências sociais quanto das naturais.

Essas visões, uma vez legitimadas pelo discurso científico, se enraízam como práticas sociais e se incorporam nas relações sociais vigentes. Vê-se, portanto, que as visões de natureza têm consequiências sociais que transcendem o âmbito acadêmico, e cujo valor e repercussão social estão além dos debates acadêmicos e conceituais que suscitam.

\section{O ressurgimento da natureza}

Embora existam distâncias e diferenças nas abordagens sobre a natureza, vindas de distintos âmbitos do conhecimento, não é menos verdadeiro dizer que, na atualidade, ela encontra um lugar de destaque na análise de significativas práticas científicas e sociais. Essa centralidade nasce, portanto, de várias fontes. Nas ciências naturais, mediante as intervenções inéditas que a biotecnologia vem realizando sobre o material genético das células, bem como seu amplo espectro de aplicações estabelecidas e ainda por estabelecer, e aquelas que estas práticas permitirão no futuro. Nas ciências sociais, pelas conseqüências sociais atuais e futuras dessas intervenções, e pelos embates sociais que o acesso à natureza e seus atributos vêm desatando em diferentes lugares do planeta. Em ambos os casos, as implicações envolvem diferentes escalas geográficas. 
As intervenções sobre o material genético das células por meio da biotecnologia e a velocidade com que a tecnociência avança no sentido de conquistar um número cada vez maior de nichos de intervenção, desde microorganismos até o próprio homem, talvez se constituam nas mais significativas práticas científicas do final do século XX e início do XXI. Hoje, a biotecnologia é considerada um dos nichos tecnocientíficos mais promissores, o que se pode comprovar pelo volume de pesquisas dedicadas a esta temática, a quantidade de verbas públicas e privadas envolvidas e o interesse que desperta em todos os níveis sociais.

As conseqüências sociais dessa nova realidade estão sendo acompanhadas pelas ciências sociais com um interesse crescente. As considerações sobre as conseqüências éticas da manipulação do código genético e formas de valorização destas práticas, passando por aproximações antropológicas, sociológicas, políticas e geográficas, demonstram o interesse que estão gerando nestas áreas do conhecimento. A natureza volta também ao centro das ciências sociais à medida que surgem embates pelo seu acesso, uso e transformação em diferentes âmbitos e escalas geográficas, que sem dúvida hoje representam formas de mobilização social a serem analisadas. As lutas em torno da questão do uso social da água, das florestas, dos produtos florestais, etc., estão longe de serem apenas lutas pela preservação dos chamados recursos. Trata-se de lutas nas quais a natureza se coloca como elemento essencial de definição do poder social, onde simultaneamente interesses econômicos e políticos estão sendo definidos. A utilização da natureza como mediação teórica ajuda não só na localização da problemática, como na sua identificação como nicho de disputa, enfatizando assim suas íntimas relações de determinação com o âmbito do social.

\section{Biodiversidade e tecnociência ${ }^{1}$}

Nas formas de ação sobre a natureza, o surgimento da biodiversidade como qualidade que determina um novo mapa do mundo segundo sua distribuição, inaugura uma forma inédita de sua 
apropriação, de consequiências importantes para a reflexão nas ciências sociais.

Essas formas de utilização e usufruto da natureza determinam um novo locus de intervenção: já não unicamente os recursos presentes no território, mas o material genético das células desses recursos. Estas formas de intervenção, indiscutivelmente mediadas pela ciência e pela tecnologia, desenvolvem-se paralelamente às novas formas de incorporação desses atributos à sociedade, tanto no âmbito econômico quanto no político. No primeiro caso, mediante a criação de biomercadorias, e, no segundo, com a criação de um novo espaço de intervenção política, com novas formas de controle desses recursos.

Essa apropriação da natureza requer a aceitação da valoração econômica dos recursos genéticos, ou seja, que ao material genético dos seres vivos seja aplicado um sistema de valores similar àquele que se aplica a um produto manufaturado. Essa aceitação garante que os atributos possam ser incorporados nas redes econômicas e, portanto, tratados como biomercadorias, mediante regras comerciais e de transações que finalizam seu processo de mercantilização.

No sentido político, cria-se um novo âmbito de intervenção, articulado por intermédio do aparelho institucional transnacional da tecnociência e baseado no conhecimento especializado (Escobar, 2000). O novo âmbito é apropriado, transformado e concretizado nos territórios de conservação, preservação ou pesquisa, para os quais se regulamentam novas formas de governo sobre os recursos, em espaços de negociação como a Convenção da Biodiversidade. ${ }^{2}$ Tratase de novas formas de governo, visto que por meio elas decide-se como os recursos são geridos, utilizados e distribuídos socialmente, sendo que o aparelho institucional transnacional é o agente que produz o conhecimento e, portanto, as regras de sua intervenção nos territórios. O espaço de intervenção política, que chamaremos de locus geo-genético, ${ }^{3}$ certamente caracteriza-se como um novo âmbito de práticas sociais e suscita questionamentos sobre o substrato conceitual mais adequado para tratá-lo a partir das ciências sociais. 
O interessante do tema da biodiversidade é que permite colocar com maior ênfase as consequiências políticas e geopolíticas dessas novas formas de intervenção. Sem se concentrar unicamente nas questões éticas destas últimas, os debates surgidos pelos embates sociais que emergem nas áreas de maior biodiversidade, como a Amazônia brasileira ou Pacífico colombiano, questionam a exclusão territorial e as condições históricas de que têm sido alvo estas regiões sob ordens econômicas, institucionais e jurídicas que hoje pretendem justificar a apropriação e privatização desses recursos para o beneficio de instituições principalmente privadas, que pouco ou nada devolvem às próprias regiões. Trata-se de um embate entre diferentes visões e formas alternativas de interação com o entorno, bem como de processos de consolidação de identidade e autonomia, e não de simples transações e compensações estabelecidas pelas regras do mercado. Aceitar uma forma equilibrada de valorização dos recursos genéticos que dê conta dos custos sociais que esses recursos demandaram para sua preservação implica algo mais que negociar o seu valor em uma matriz de custo-benefício.

De uma perspectiva geopolítica, a apropriação dos recursos genéticos, mesmo sob condições de aceitação unânimes entre os grupos envolvidos, traz conseqüências que devem ser levadas em conta e que não são tão evidentes. Trata-se da incorporação do locus geogenético às redes tecnocientíficas e ao significado material e simbólico desta incorporação. Estas intervenções sobre a natureza implicam a conquista de uma das últimas fronteiras da materialidade, o material genético das células, que promete simultaneamente a conquista do futuro. O material genético serve como plataforma dessa conquista, na medida em que representa a possibilidade de se moldar a vida para a construção de um futuro que estará nas mãos de quem comandar essa arquitetura. A tecnociência ergue-se; assim, como uma fonte de poder no presente, que promete e garante o poder hegemônico no futuro. A conquista do futuro se estabelece, portanto, em termos materiais e a biotecnologia garante a capacidade de intervenção e posterior conversão em poder econômico e político. Todavia, é preciso não esquecer que a conquista também se dá em termos simbólicos. A 
"conquista do futuro" refere-se também à concretização do mito da tecnociência, colonizando todos os âmbitos da vida. A tecnociência apresenta-se assim como um novo elemento legitimador das práticas sociais que rege e determina a moldagem dos indivíduos e, portanto, $o$ ator que comanda a engenharia da própria sociedade. Assim, muito mais que compensações econômicas, estão em jogo as formas de interação entre a tecnociência, os Estados e os grupos sociais onde se encontram os recursos.

O poder da tecnociência também se dá pela redução material a que submete seus objetos. A partir dela, uma espécie animal ou vegetal fica reduzida ao seu material genético, encontrando-se neste âmbito a fonte do seu valor científico, econômico e social. Surge assim um empobrecimento também ontológico, à medida que uma floresta ou um território biodiverso é valorizado não como tal, mas como fonte de genes para a pesquisa biotecnológica.

De outra parte, é paradoxal que, enquanto a atividade científica, e particularmente a biotecnológica, extrai sua legitimidade e prestígio social da sua suposta capacidade de controle sobre seus ensaios e procedimentos (sobre a própria natureza) e da segurança com que estes são realizados, na manipulação dos recursos genéticos se permite uma "flexibilização" da vida mesma, entendida apenas como informação genética que pode ser modificada, tratada e transformada com e através de outros organismos.

A questão da privatização destes recursos genéticos, as formas como estão sendo patenteados e as consequiências sociais, tanto em nível nacional, quanto local, dessas práticas, são enormes. A Convenção da Biodiversidade reconhece a soberania dos Estados sobre os recursos genéticos presentes nos respectivos territórios quando diz no seu Artigo 15:

Em reconhecimento dos direitos soberanos dos Estados sobre seus recursos naturais, a autoridade para determinar o acesso a recursos genéticos pertence aos governos nacionais e está sujeita à legislação nacional (Convenção..., 1992). 
Os termos em que se realizam as negociações e suas consequiências nas relações internas, entre os diferentes níveis políticos de decisão, e externas, nas relações internacionais, devem ser encarados como opções dos próprios Estados, diante das diversas possibilidades de utilização dos recursos. Essas opções, que envolvem decisões políticas e considerações geopolíticas, dizem respeito ao conjunto da sociedade, já que se trata de atributos que constitucionalmente pertencem à Nação, no caso brasileiro. Neste sentido, uma maior reflexão faz-se necessária a partir de diferentes âmbitos da vida social, dentre eles e com muita ênfase, o âmbito acadêmico. Esta reflexão deve incorporar argumentos e visões que dêem conta do amplo universo de elementos envolvidos nesta temática e considerar que as visões produzidas a partir da academia podem desempenhar importante papel na legitimação de práticas sociais e processos de tomada de decisões.

\section{A equação natureza-sociedade}

Esta equação, se pensada no contexto das práticas sociais de intervenção do material genético acima descritas, fica um pouco limitada, ainda que tomada como mero recurso heurístico. Aprofundase nela a separação entre os dois termos e, portanto, dificulta-se a compreensão das relações determinantes entre eles, neste novo contexto de mediação da tecnociência. Pode-se perceber, por vezes, uma insinuação dicotômica que esgota as possibilidades e a extensão dessas relações, onde o natural se coloca como o elemento de contraste externo ao social e vice-versa. Além disso, esta dicotomia abre a porta para transformações metafóricas onde o natural é tomado como sinônimo de inato e o social como sinônimo de construído-artificial. Retira-se assim todo o natural do social e todo o social da natureza.

No entanto, e paradoxalmente, esta equação nasce da aceitação do âmbito social na natureza, à medida que esta é transformada pela ação do trabalho, na chamada segunda natureza. Aceita-se inicialmente a natureza biológica do homem como indiscutível e inelutável; aceita-se a transformação da natureza mediante o trabalho, 
engendrando assim o nascimento da segunda natureza, isto é, a natureza socializada, valorizada (Moraes, 1994). No entanto, a segunda natureza parece desconhecer o natural da natureza, colocando-o agora no exclusivo âmbito da história. A história, então, toma conta da biologia e da física?

Isto representa problemas para as ciências sociais? Talvez seja pertinente considerar que aquilo que se chama de "natural" da natureza, normalmente colocada dentro dos processos de interesse das ciências naturais, apresenta conteúdos e está definido por práticas sociais que esbarram necessariamente nas ciências sociais. Algumas dinâmicas que hoje são percebidas como do âmbito da biologia, da genética, da química e até mesmo da física, começam a ter enorme importância para as abordagens feitas pelas ciências sociais.

Essas dinâmicas podem ser vistas de duas formas. A primeira, como meio de controle sobre os processos biológicos que hoje entendemos como de competência das ciências naturais. No entanto, este tipo de ação realiza-se em muitos lugares do mundo e, há muitos anos, mediante práticas sociais como a agricultura e os processos de seleção das sementes. Trata-se de uma verdadeira intervenção no processo de seleção natural que tem determinado variedades mais ou menos aptas para a agricultura camponesa, e que hoje estão sendo objeto da cobiça das grandes multinacionais, tanto as sementes quanto o conhecimento local sobre elas (Shiva, 1993).

A segunda diz respeito às formas de controle e domínio sobre a natureza, desde a extração dos produtos primários e matérias primas, até as mais sofisticadas, como aquelas sobre os recursos genéticos. Trata-se da concretização de um novo espaço de poder social que, embora por meio da natureza, em última instância, implica em domínio sobre o próprio homem. Nessa medida, a natureza sempre foi uma fonte de poder social. Mas ela é ubíqua, sobreposta ao contínuo da sociedade e interage nesse contínuo. Como então insistir em separar os termos? A dicotomia parece tornar-se limitante.

A equação natureza-sociedade é utilizada para distinguir, e não necessariamente separar, duas ordens de materialidade que nela 
confluem, e que reclamam articulações mais precisas. Essas articulações não determinam uma fusão das duas ordens, apenas a explicitação mais detalhada das integrações, que se efetivam por meio das relações sociais, e dos fenômenos empíricos que essas relações criam (Leff, 1998). É na explicitação dessas articulações que a natureza mostra seu potencial como categoria explicativa para as ciências sociais.

Até aqui foram apresentadas algumas problematizações com relação à equação natureza-sociedade. $\mathrm{Na}$ base desse equacionamento, parece estar uma visão de natureza entendida como somatória de seres, de recursos, desprovida de seu potencial organizador, que se integra aos processos de organização da sociedade por meio das próprias relações sociais (Escobar, 2000). O fato de que a natureza seja o resultado, primeiro, de uma construção que depende do conhecimento socialmente produzido e, segundo, das modificações vindas da ação humana, não a despoja da sua dinâmica e materialidade biológica e física. E hoje são justamente seus referentes biológico e físico, talvez mais do que nunca, os meios mediante os quais a natureza está sendo articulada nas relações sociais, de forma inédita. É por esta razão que esses referenciais são importantes para as abordagens feitas pelas ciências sociais.

É pertinente lembrar a reflexão de Ingold (1996), quando ele afirma que embora o conceito de natureza seja socialmente construído, isto é, que seu sentido esteja sujeito a uma constante negociação nos múltiplos contextos sociais e discursivos, não se deve perder de vista que existem elementos do mundo aos quais este conceito está vinculado. Assim, a natureza não é um estágio prévio da existência, mas envolve mundos além daqueles habitados pelo homem. Nessa ordem de idéias e apelando para uma visão construtivista, Ingold continua seu raciocínio reafirmando a pertinência de incluir o mundo natural e físico nessa construção do mundo social, já que este molda o mundo humano tanto quanto é moldado por ele.

\section{Natureza, ambiente e desenvolvimento sustentável}

A questão da natureza nas ciências sociais continua em um estágio de tensão, onde existe uma série de empecilhos para seu uso 
como categoria explicativa. Apenas a segunda natureza tem sido utilizada com continuidade em algumas abordagens, sendo que a natureza relaciona-se com visões positivistas, especialmente evocativas do naturalismo do século XIX, nas quais seus princípios, leis e materialidades são exteriores e independentes do social e do todo do conhecimento (Descola, 2002).

Frente a essa tensão, deu-se o deslocamento da natureza e a incorporação do ambiente como conceito integrador. Este foi permeando lentamente o discurso ecológico no período do pós-guerra e acabou veiculando uma visão da natureza segundo o sistema urbanoindustrial. Sua escolha pode ser conseqüência de uma neutralidade que lhe foi atribuída, e que evitava as conotações dualistas que o termo natureza evocava. Parecia ser um termo auto-evidente, que não requeria justificativa, e oportuno para tratar da difícil região onde o homem e suas feições e conexões biológicas se comprometem com suas realizações sociais. No entanto, o dualismo não desaparece, ainda que pareça atenuado com a substituição.

O termo natureza continua tendo um forte apelo cultural e político, enquanto o termo ambiente pertence mais ao léxico de especialistas que conformam hoje o amplo espectro institucional que toma conta das questões ecológicas. Desta forma, é um elemento fundamental na construção social do lugar e dos referenciais culturais.

\section{O lugar do desenvolvimento sustentável}

Há mais de duas décadas, o "ambiente" vem tomando conta dos temas relativos às relações natureza-sociedade, como já dito. De igual forma irrompe no cenário o "desenvolvimento", cujas significações não constituem objeto de análise do presente artigo. Os dois termos eram vistos como discursos paralelos, porém distintos. $\mathrm{O}$ problema do desenvolvimento centrava-se apenas no fato dele ser ainda uma aspiração, e não uma realidade, para algumas regiões do planeta. Nesse sentido, havia obstáculos estruturais que impediam que suas vantagens fossem espalhadas mais amplamente. Foi somente 
com o Relatório Brundtland ${ }^{4}$ que teve início a integração dos dois discursos.

Inicialmente, os modelos que permeavam o campo do ambiental eram apenas de dois tipos: aqueles que iniciavam sua análise com base na natureza, e que salientavam as funções que o ambiente proporcionava ao ser humano, sendo o marco conceitual e epistemológico que originou as ciências ambientais. Em segunda instância, aqueles que iniciavam sua análise com o social, que sugeriam que o ambiente colocava limites à adaptabilidade humana, de onde nasce o paradigma da ecologia humana (Redclift, 2000).

Começava a ficar claro que o critério ambiental estava composto por diferentes racionalidades e era entendido desde diferentes comunidades epistêmicas. A concepção de natureza inerente a essas abordagens continuava permeada de considerações de exterioridade e era predominantemente utilitarista. Nesta medida, os assuntos de interesse giravam em torno da exploração de recursos, sua localização, das espécies selvagens e dos recursos atmosféricos, marinhos e terrestres.

Foi mediante as mudanças climáticas e as considerações da Eco 92 que se reorganizaram as problemáticas ambientais e suas causas, de forma que a abundância e não a escassez passou a ser avaliada como fonte de preocupação e, nessa medida, algumas atividades econômicas passaram a ser o centro das críticas, pois eram vistas como promotoras de degradação ambiental. Simultaneamente, consolidou-se a escala global de análise como referencial adequado para abordar as questões ambientais e acessar sua problemática.

A idéia moderna do controle da natureza pela ciência e a tecnologia ficou abalada e a condição externa da natureza questionada, na medida em que os problemas ambientais, os chamados Global Commons, ${ }^{5}$ se reconheceram como ubíquos, sem fronteiras territoriais e invadindo todos os tipos de sociedades. As constatações empíricas dos fenômenos levaram à exploração de abordagens mais holísticas, que consideraram a natureza transversal ou trans-setorial destes assuntos. Essas considerações multidimensionais requeriam uma 
abordagem conceitual que não podia ser exclusivamente a das ciências naturais, já que alguns dos componentes das mudanças e da problemática eram também reconhecidamente sociais. A partir de todas estas reflexões foi composta a expressão "desenvolvimento sustentável" como termo que abrange uma série de visões sobre o ambiental, com a pretensão e o cuidado de evitar anteriores reducionismos ou a transposição de metáforas de um campo científico para outro. O termo apontava para um futuro onde o ambiental fosse incorporado às atividades sociais, embora não desprovido de contradições; ele teve uma difusão muita ampla, principalmente no setor da tecnocracia, porém permeou também as instâncias acadêmicas e privadas.

Tentativas de quantificação do valor dos atributos do ambiente, mediante modelos para internalizar os custos ambientais das atividades econômicas, foram desenvolvidas, colocando assim a questão também no âmbito do mercado. $\mathrm{O}$ argumento para justificar esta incorporação foi que a falta de quantificação de certos atributos naturais que entram no processo produtivo de algumas atividades econômicas induzia a uma negligência com as questões ambientais. Desta forma, pretendiase controlar os custos ambientais vindos do impulso "desenvolvimentista" de algumas atividades econômicas, mediante sua inserção nesta lógica.

De todos esses conteúdos sobre a temática do desenvolvimento sustentável, é possível inferir que não se trata de um processo linear e convergente, mas de um conjunto de visões, em muitas ocasiões divergente e contraditório. Em volta dessa expressão, tecem-se abordagens de origens díspares. Seu significado e, portanto, as ações que de seu entendimento se derivam, são heterogêneas, podendo-se dizer que existe uma polissemia na expressão. As discussões que ela suscita problematizam o papel da ciência, a localização e o caráter da natureza como conhecimento e como realidade empírica, a questão da escala de abordagem mais conveniente para os fenômenos que abrange, e também, a relação dos seus assuntos com as ciências sociais.

Pode-se, portanto, afirmar que o desenvolvimento sustentável, devido às suas contradições e visões, às vezes divergentes, não é um 
paradigma unificador, sendo mais um gerador de questões sobre as quais se direcionam as atenções para que os temas sejam apropriados e iluminados por diferentes setores e perspectivas (Redclift, 2001). Nesse sentido, ele tem sido uma fonte para as ciências sociais que, de diferentes ângulos epistemológicos, abre, aprimora e/ou questiona seus caminhos conceituais. Isso tem trazido uma contribuição importante ao próprio desdobramento das ciências sociais. Repensar a natureza, questionar ou revitalizar seu uso como conceito neste âmbito, implica uma enorme re-interpretação das visões de mundo que têm permeado as epistemologias destas ciências.

A transversalidade das questões ambientais, o debate em curso sobre o desenvolvimento sustentável, a evolução dos pressupostos, tanto do desenvolvimento quanto da sustentabilidade, obrigam as ciências sociais a assumirem um posicionamento, a contestarem e a aprimorarem as perspectivas que incorporam ao debate e a partir das quais pretendem apresentar suas contribuições para a resolução da problemática ambiental. $\mathrm{O}$ fato de a sustentabilidade pertencer a uma área que não pode ser pesquisada com exclusividade, nem pelas ciências naturais nem pelas sociais, tem levado à acentuação das diferenças epistemológicas entre essas ciências, mas também à consideração do potencial inerente às abordagens interdisciplinares, embora no interior das ciências sociais existam ênfases e compreensões divergentes sobre esta questão e sobre os assuntos ambientais.

De outra parte, essas questões trazem implicações políticas já que dizem respeito aos processos sociais envolvidos na problemática ambiental e na sua resolução. Isso passa necessariamente pela consideração do poder social envolvido nessas práticas, que as converte em hegemônicas ou em subalternas. Nessa medida, o ambiental serve de cenário reflexivo onde se reconhecem as formas ideológicas, políticas e sociais das relações nas sociedades contemporâneas.

\section{Considerações finais}

Foram apresentadas algumas questões tanto sobre uso do termo natureza, quanto do ambiente, e o seu correlato, o desenvolvimento 
sustentável. Cada um deles lança seus desafios e questionamentos às ciências sociais, obrigando-as a refletir sobre a necessidade de reconhecer suas utilidades e suas evoluções, considerando os níveis de metamorfose e aprimoramento que cada um tem sofrido a partir da abordagem social.

Em certos contextos e conjunturas, a natureza mostra-se como conceito promissor, na medida em que permite interpretar as articulações, cada vez mais próximas, entre as ordens de materialidade consideradas pelas ciências naturais e sociais. No caso dos recursos genéticos, permite a identificação de nichos de abordagem importantes, por suas implicações políticas e geopolíticas, que o termo ambiente não salienta.

Este último, por sua vez, aparece como unificador e, portanto, como conceito que supera as dualidades e dicotomias que o binômio "natureza-sociedade" impunha. No entanto, ele está carregado de significações oriundas de sua incorporação pela tecnocracia ambiental global, onde ele se fixou sem maiores questionamentos.

O desenvolvimento sustentável, como termo unificador e problematizador dos seus dois componentes, acaba colocando questões para as ciências sociais. Cada termo apresenta, assim, suas vantagens e dificuldades, mostrando que seus usos não correspondem a uma sucessão hierárquica nem evolutiva e que é possível o resgate de cada um, desde que nas contingências e contextos adequados.

\section{Notas}

1 O termo biodiversidade, segundo a definição da Convenção (1992) que a rege, refere-se à "variabilidade de organismos vivos de todas as origens, compreendendo, dentre outros, ecossistemas terrestres, marinhos e outros ecossistemas aquáticos e os complexos ecológicos de que fazem parte; compreendendo ainda a diversidade dentro de espécies, entre espécies e de ecossistemas". O termo também é discutido em Global Biodiversity Strategy (WRI, 1991), onde é incorporado como novo discurso e valor no âmbito da natureza e do ambiente. Por sua parte, a tecnociência indica um tipo de saber caracterizado por seu formalismo, sistematicidade e 
abstração, onde se amalgamam a tecnologia e a ciência de forma não unilateral, sendo difícil distinguir a parte que fornece os recursos teóricos daquela que fornece os instrumentos para a realização do saber (Oliveira, s.d.).

2 Assinada durante a ECO 92, no Rio de Janeiro, esta Convenção teve por objetivos a conservação da biodiversidade, o uso sustentável de seus componentes e a divisão eqüitativa e justa dos benefícios gerados com a utilização de recursos genéticos.

3 Este denominação segue a idéia de Ó Tuathail (2000) quando fala do locus geo-ecológico.

4 Este Relatório apresenta os resultados que emergiram da Comissão Mundial de Meio Ambiente e Desenvolvimento, instituída em 1987, sob os auspícios do Programa das Nações Unidas para o Meio Ambiente (PNUMA), também conhecido como "Nosso Futuro Comum". O nome "Relatório Brundtland" deve-se ao fato de que a presidência da Comissão esteve sob a responsabilidade da então Primeira Ministra da Noruega, Gro Harlem Brundtland.

5 Essa expressão é usada para representar os temas que envolvem os recursos que estão além do controle de qualquer governo individualmente, tais como a atmosfera, os oceanos, o espaço e a Antártida.

Abstract: The construction of the term nature involves different areas of knowledge and has been the object of inquiry of both natural and social sciences. The knowledge produced under the auspices of this concept falls into several categories that can be studied from the perspective of the social sciences. This paper intends to analyze some of these approaches, and to establish their relationships to the new social practices that are determining new forms of intervention in nature. The purpose of this analysis is to question some of the assumptions of the social sciences in this respect, as generators of knowledge on the matter. The substitution of nature by the term environment is also taken into account as well as the irruption of sustainable development, thus completing the conceptual scenario that takes over the issues of nature-society relations, from the view of the social sciences.

Key-words: nature, social sciences, nature-society relations, environment, sustainable development. 
Resumen: La construcción del sentido del término naturaleza abarca diferentes áreas del conocimiento y ha sido objeto de reflexión tanto de las ciencias naturales como sociales. Los desdoblamientos del conocimiento producido sobre este tema muestran que existen diversos abordajes que pueden ser identificados desde la perspectiva de las ciencias sociales. El objetivo de este artículo es considerar algunos de esos abordajes y relacionarlos con las nuevas prácticas sociales que determinan formas de intervención inéditas sobre la naturaleza y que sugieren cuestionamientos para estas ciencias, como productoras de conocimiento sobre este tema. De igual manera, se explicita la substitución de este término por el de ambiente e, posteriormente, el aparecimiento del término desarrollo sostenible como parte del acervo conceptual con que es abordada la problemática alrededor de las relaciones naturaleza-sociedad en las ciencias sociales.

Palavras llave: naturaleza, ciencias sociales, relaciones naturalezasociedad, ambiente, desarrollo sostenible.

\section{Referências bibliográficas}

CONVENÇÃO SOBRE DIVERSIDADE BIOLÓGICA. 1992. Disponível em: <www.biodiv.org/convention/articles.asp>.

DESCOLA, P. La antropología y la cuestión de la naturaleza. In: Repensado la Naturaleza. Bogotá: Universidad Nacional de Colombia/Sede Leticia, Instituto Amazónico de Investigaciones (IMANI), Instituto Colombiano de Antropología e Historia (ICANH), Colciencias, 2002.

DESCOLA, P.; PÁLSSON, G. (Eds.). Nature and society: anthropological perspectives. Londres: Routledge, 1996.

ESCOBAR, Arturo. El final del salvaje. Bogotá: CEREC, ICAN, 2000.

La invención del tercer mundo: construcción y desconstrucción del desarrollo. Bogotá: Editorial Norma, 1998.

INGOLD, T. The optimal Forager and Economic Man. In: DESCOLA P.; PÁLSSON, G. (Eds.). Nature and society: anthropological perspectives. Londres: Routledge, 1996.

LEFF, Enrique. Saber ambiental: sustentabilidad, racionalidad, complejidad. México: Siglo XXI, UNAM, PNUMA, 1998.

MORAES, A. C. R. Meio ambiente e ciências sociais. São Paulo: HUCITEC, 1994. 
OLIVEIRA, M. B. Desmercantilizar a tecnociência. In: SANTOS, Boaventura de Souza (Org.). Um discurso sobre as Ciências revisitado. No prelo.

Ó TUATHAIL, G. The postmodern geopolitical condition: states, statecraft and security at the Millennium. Annals of the Association of American Geographers, v. 90, n. 1, p. 166-178, 2000.

REDCLIFT, M. Environmental security and the recombinant human: sustainability in the twenty-first century. Inaugural Lecture at King's College. 2001.

SHIVA, V. Monocultures of the mind: perspectives of Biodiversity and Biotechnology. Londres: Zed Books, 1993.

WRI (World Resource Institute); IUCN (World Conservation Union); UNEP (United Nations Environment Program). Global Biodiversity Strategy. Washington: WRI/Iucn/Unep, 1991. 